\title{
Syntheses of 6-Acetamido-6-deoxy-lactose Derivatives ${ }^{1)}$
}

\author{
Setsuzo Tejima and Taku Chiba \\ Faculty of Pharmacentical Sciences, Nagoya City University ${ }^{2)}$
}

(Received September 1, 1972)

\begin{abstract}
A facile synthesis of lactosan hexaacetate (2) was described. 6-Acetamido-6-deoxylactose (9) was synthesized starting from 2 via hepta-O-acetyl-6-O-methylsulfonyl- $\beta$-lactose (3), benzyl hexa-O-acetyl-6-O-methylsulfonyl- $\beta$-lactoside (4), and benzyl hexa-O-acetyl-6azido-6-deoxy- $\beta$-lactoside (6), followed by catalytic reduction of compound (6), successive acetylation and deacetylation. Compound (9) did not show antibacterial activity against twenty microorganisms.

Methyl 6-acetamido-6-deoxy- $\beta$-lactoside (14) was also synthesized using the analogous synthetic route. Syntheses and properties of seven new lactose or lactoside derivatives were also described.
\end{abstract}

The syntheses and chemistry of amino sugars of oligosaccharide series have been extensively developed in recent years often for biological interest. Among the numerous papers reported, syntheses of disaccharides involving 2-acetamido-2-deoxy-D-glucopyranose by modified Koenigs-Knorr reaction have been dealt with in many workers. ${ }^{3)}$ On the one hand, preparation of amino oligosaccharides having one to several amino groups in place of the primary hydroxyls by way of chemical modification of naturally occurring oligosaccharides have been forcused considerable attentions. For example, $6^{\prime}$-amino- $6^{\prime}$-deoxymaltose ${ }^{4}$ ) and 6, $6^{\prime}$-diamino-6, $6^{\prime}$-dideoxymaltosylamine ${ }^{5}$ ) were prepared from maltose. The analogous syntheses of amino derivatives of Schardinger $\alpha$-dextrin and raffinose, $,^{6)} 6,6^{\prime}$-diazido- $6,6^{\prime}$-dideoxy$\alpha, \alpha$-trehalose, ${ }^{7)}$ 6-amino-6-deoxy- and 6,6'-diamino-6, $6^{\prime}$-dideoxysucrose or $\alpha, \alpha$-trehalose, ${ }^{8)}$ $1^{\prime}, 6,6^{\prime}$-triamino-1',6,6'-trideoxy-sucrose and 6,6'-diamino-6, $6^{\prime}$-dideoxy-trehalose ${ }^{5 \text { ) }}$ have been reported. Recently, Hough, et al. in their studies on the chemical modification of trehalose ${ }^{9}$ and sucrose, ${ }^{10}$ have also reported on the syntheses of azides or amino disaccharides.

In lactose series, according to the lirteature, amino derivatives having amino or acetamido group in C-1 or C-2 position have been synthesized; syntheses of 1 -aminolactose (4- $\beta$-Dgalactopyranosyl-1-amino-1-deoxy- $\beta$-D-glucopyranose), ${ }^{11)}$ 1-acetamidolactulose (4- $\beta$-D-galactopyranosyl-1-acetamido-1-deoxy-D-fructose), ${ }^{12)} \mathrm{N}$-acetyl-lactosamine (4- $\beta$-D-galactopyranosyl-

1) This paper forms Part II of the series entitled "Chemical Modification of Lactose"; Part I: S. Tejima, Carbohyd. Res., 20, 123 (1971).

2) Location: Tanabe-dori, Mizuho-ku, Nagoya.

3) See for example: K. Heyns, R. Harrison, and H. Paulsen, Chem. Ber., 100, 271 (1967); K. Heyns, K. Propp, and R. Harrison, ibid., 100, 2655 (1967); M.A.E. Shaban and R.W. Jeanloz, Carbohyd. Res., 20, 399 (1971), 21, 347 (1972); D. Bundle and N. Shaw, ibid., 21, 211 (1972).

4) G.G.S. Dutton and K.N. Slessor, Can. J. Chem., 44, 1069 (1966).

5) S. Umezawa, T. Tsuchiya, S. Nakada, and K. Tatsuta, Bull. Chem. Soc. Japan., 40, 395 (1967).

6) S. Umezawa and K. Tatsuta, Bull. Chem. Soc. Japan, 41, 464 (1968).

7) G. Birch and A.C. Richardson, Carbohyd. Res., 8, 411 (1968).

8) I. Jezo, Chem. Zvesti, 25, 364 (1971).

9) Y. Ali, L. Hough, and C.K. DeBruyne, Carbohyd. Res., 14, 181 (1970); L. Hough, A.C. Richardson, and E. Tarelli, J. Chem. Soc. (C), 1971, 1732.

10) C.H. Bolton, L. Hough, and R. Khan, Carbohyd. Res., 21, 133 (1972).

11) F. Micheel, R. Frier, E. Plate, and A. Hiller, Chem. Ber., 85, 1092 (1952); R. Kuhn and G. Krüger, ibid., 87, 1544 (1954).

12) R. Kuhn and W. Kirschenlohr, Chem. Ber., 87, 1547 (1954). 
2-acetamido-2-deoxy-D-glucopyranose), ${ }^{13}$ ) N-p-nitrophenyl lactosylamine, ${ }^{14)}$ and lactose or lactosamine derivatives linked to L-asparagine ${ }^{15)}$ have been described. Therefore, amino or acetamido group has not yet been introduced in other positions in lactose.

In the previous paper of this series, ${ }^{1)}$ Tejima reported on the introduction of sulfur atom instead of the oxygen in the hydroxymethyl group of the reducing moiety in lactose. In this paper, the authors have now synthesized the title compounds which may be interesting from biological viewpoints, since 6-acetamido-6-deoxylactose is a structural isomer of $\mathrm{N}$ acetyl-lactosamine; it has been well known that $\mathrm{N}$-acetyl-lactosamine is one of the repeating units in mucopolysaccharides and it has often been isolated from partial acid hydrolyzates of naturally occurring polysaccharides. ${ }^{16)}$

In a similar manner as Part I, the authors selected lactosan hexaacetate (2) as a starting material of the present work. However, the previous preparative method of $\mathbf{2}$ required a prolonged heating with large volumes of aqueous alkali in the step of alkaline degradation of phenyl hepta-O-acetyl- $\beta$-lactoside. Therefore, a more facile synthesis of $\mathbf{2}$ was investigated. According to the paper on alkaline degradation of aryl $\beta$-glycosides of monosaccharides, ${ }^{17}$ ) 1,6 -anhydro formation was affected by the substituents on the phenyl. For example, in aryl $\beta$-D-glucopyranosides, $o$ - or $p$-nitro-phenyl cleaved faster than phenyl, while $o$-cresyl was slower to form 1,6-anhydro- $\beta$-D-glucopyranose; the latter required, with the same alkalinity, more than twice as long as heating than phenyl. Our preliminary test which checked the decrease of the starting glycosides and formation of lactosan using thin-layer chromatography (TLC) clarified that, among several aryl hepta-O-acetyl- $\beta$-lactosides tested, 0 -chlorophenyl hepta-O-acetyl- $\beta$-lactoside (1) was the most suitable one for a facile synthesis of $\mathbf{2}$; lactosan formation goes to completion by refluxing $\mathbf{1}$ with about sixfold aqueous alcoholic alkali for six hours and the resulting lactosan is separated as fully acetate in a yield of $90 \%$. More rapid lactosan formation could be attained from $o$-nitrophenyl hepta-O-acetyl- $\beta$-lactoside, however, deep coloration resulted simultaneously which resisted to decolorization and decreased the yield of 2 .

Hepta-O-acetyl-6-O-methylsulfonyl- $\beta$-lactose (3) was prepared according to the previous method; Zemplén degradation of $\mathbf{2}$, followed by the Koenigs-Knorr reaction and successive mesylation of the resulted heptaacetate. Heating of $\mathbf{3}$ with sodium azide in N,N-dimethylformamide or hexamethylphosphoric triamide (HMPA) at $100^{\circ}$ showed to yield a complex mixture by TLC, and a homogeneous product having azido group could not be separated. Therefore, the authors, in the next step, designed to start from the corresponding benzyl lactoside (4).

Benzylglycosidation by warming a mixture of benzylalcohol with syrupy bromide of $\mathbf{3}$ in the presence of mercuric cyanide afforded benzyl hexa-O-acetyl-6-O-methylsulfonyl$\beta$-lactoside (4) in a yield of $45 \%$. Another method of benzylglycosidation using zinc oxide as the acid acceptor, originally reported by Helferich and Wedemeyer ${ }^{18)}$ for the preparation of benzyl tetra-O-acetyl- $\beta$-D-glucopyranoside, resulted (4) with a low yield. Treatment of 4 with sodium iodide in boiling acetonitrile caused replacement of the mesyloxy group by iodine and crystalline benzyl hexa-O-acetyl-6-deoxy-6-iodo- $\beta$-lactoside (5) was obtained in a yield of $90 \%$; this confirmed that the mesyloxy group in $\mathbf{4}$ was located on the primary alcohol group.

Introduction of azido group in $\mathbf{4}$ was smoothly performed by heating a mixture of $\mathbf{4}$ with sodium azide in HMPA at $100^{\circ}$ and crystalline benzyl hexa-O-acetyl-6-azido-6-deoxy- $\beta$ -

13) R. Kuhn and W. Kirschenlohr, Ann., 600, 135 (1956); T. Okuyama, Tohoku J. Expl. Med., 68, 313 (1958).

14) S. Adachi, Carbohyd. Res., 10, 165 (1969).

15) M. Spinola and R.W. Jeanloz, Carbohyd. Res. 15, 361 (1970).

16) R.W. Bailey, “Oligosaccharides," Pergamon Press, London, 1965, p. 122.

17) E.M. Montgomery, N.K. Richtmyer, and C.S. Hudson, J. Am. Chem. Soc., 65, 3 (1943).

18) B. Helferich and K.F. Wedemeyer, Ann., 563, 139 (1949). 


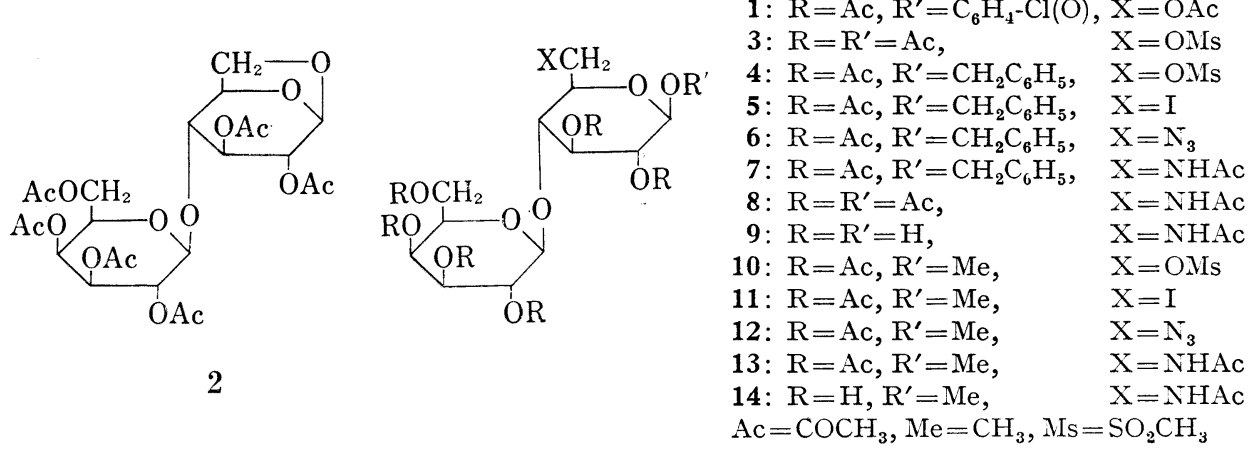

Chart 1

lactoside $(\mathbf{6})$ was separated in a yield of $74 \%$. Catalytic reduction of $\mathbf{6}$ using Raney nickel as the catalyst, followed by acetylation, afforded benzyl hexa-O-acetyl-6-acetamido-6-deoxy$\beta$-lactoside (7) in a yield of $23 \%$. The low yield was attributable to the concomitant formation of the debenzylated, hepta-O-acetyl-6-acetamido-6-deoxy- $\beta$-lactose (8). Needless to say, compound 8 was obtained from $\mathbf{6}$ in one step under the presence of large amounts of the catalyst, or from $\mathbf{7}$, followed by acetylation. The anomeric configuration of $\mathbf{8}$ was tentatively assigned $\beta$ from the synthetic route and as it showed a value of levo-rotatory. Deacetylation of 8 with methanolic sodium methoxide as the usual way yielded 6-acetamido-6-deoxy-lactose (9) as a hygroscopic, white powder. The structure was undoubtedly confirmed from the the unequivocal synthetic route and the fact that D-galactose and 6-amino-6-deoxy-D-glucose hydrochloride were identified by paper chromatography after hydrochloric acid hydrolysis of 9.

Analogous reactions were performed on the corresponding methyl hexa-O-acetyl-6-Omethylsulfonyl- $\beta$-lactoside (10), prepared by methylglycosidation of $\mathbf{3}$. Starting from 10, via methyl hexa-O-acetyl-6-azido-6-deoxy- $\beta$-lactoside (12) and methyl hexa-O-acetyl-6acetamido-6-deoxy- $\beta$-lactoside (13), methyl 6-acetamido-6-deoxy- $\beta$-lactoside (14) was synthesized. Preparation of methyl hexa-O-acetyl-6-deoxy-6-iodo- $\beta$-lactoside (11) was also described.

\section{Experimental}

Melting points were determined on a ranagimoto micro melting point apparatus and uncorrected. Solutions were evaporated in a rotary evaporator below $40^{\circ}$ under diminished pressure. Optical rotations were measured with a Yanagimoto Model OR-10 polarimeter in a $0.5 \mathrm{dm}$ tube. Infrared (IR) spectra were recorded with a Jasco Model IR-S spectrophotometer. Nuclear magnetic resonance (NMR) spectra were recorded at $60 \mathrm{MHz}$ with a Jeol Model JNM-MH-60 spectrometer. Tetramethylsilane was used as the internal standard in $\mathrm{CDCl}_{3}$. Chemical shifts are given on the $\tau$ scale. TLC on Silica Gel GF 25 $_{4}$ (E. Merck, Darmstadt, Germany) activated at $110^{\circ}$ was performed with solvent systems (A) $3: 1(\mathrm{v} / \mathrm{v}) \mathrm{CHCl}_{3}-\mathrm{acetone}$, (B) 2:1 ether-benzene, and (C) 2:1 70\% iso-PrOH-AcOEt. Detection was effected with $\mathrm{H}_{2} \mathrm{SO}_{4}$ or UV light (short wave length). Column chromatography was performed on a column of Wako-gel C-200 as the adsorbent, with $1 \mathrm{~g}$ of the mixture to be separated per $20 \mathrm{~g}$ of adsorbent. Paper chromatography was performed on Toyo Filter Paper No. 50 by the ascending method, with $6: 4: 3(\mathrm{v} / \mathrm{v}) n$-BuOH-pyridine- $\mathrm{H}_{2} \mathrm{O}$, and detection effected with (A) $0.2 \%$ ninhydrin solution dissolved in $\mathrm{H}_{2} \mathrm{O}$-saturated $n$ - $\mathrm{BuOH},{ }^{19)}$ (B) Tollens reagent, ${ }^{20)}$ (C) Sodium hypochlorite reagent. ${ }^{21)}$

Lactosan Hexaacetate (2)—o-Chlorophenyl hepta-O-acetyl- $\beta$-lactoside (1), mp $193^{\circ},[\alpha]_{\mathrm{D}}^{28}-36.3^{\circ}$ $\left.\left(c=1.13, \mathrm{CHCl}_{3}\right)\left(\mathrm{lit}^{22}\right) \mathrm{mp} 188-190^{\circ},[\alpha]_{\mathrm{D}}^{23}-38.3^{\circ}\right)$ was synthesized according to the method described by

19) D. Aminoff and W.T.J. Morgan, Nature, 162, 579 (1948); A.R. Patton and P. Chism, Anal. Chem., 23, 1683 (1951).

20) W.E. Trevelyan, D.P. Procter, and J.S. Harrison, Nature, 166, 444 (1950).

21) S.C. Pan and J.D. Dutcher, Anal. Chem., 28, 836 (1956).

22) I.C.M. Dea, Carbohyd. Res., 12, 297 (1970). 
Dea, $\left.{ }^{22}\right)$ or fusion method; fusion of octa-O-acetyl- $\beta$-lactose $(50 \mathrm{~g}, 74 \mathrm{mmole})$ and $o$-chlorophenol (68 g, 531 mmole) in the presence of $p$-toluenesulfonic acid $(0.7 \mathrm{~g})$ and $\mathrm{Ac}_{2} \mathrm{O}(2.6 \mathrm{ml})$, followed by treatment with the similar procedure as described in Part I for preparation of phenyl hepta-O-acetyl- $\beta$-lactoside, was shown to yield $1(12.7 \mathrm{~g}, 23 \%)$.

A mixture of $1(60 \mathrm{~g}, 80 \mathrm{mmole})$ with $2.6 \mathrm{M} \mathrm{KOH}(360 \mathrm{ml}, 936 \mathrm{mmole})$ in aq. EtOH $(1: 1$, v/v) was refluxed for $6 \mathrm{hr}$. The solution was made neutral at $0^{\circ}$ with $2 \mathrm{M}_{2} \mathrm{SO}_{4}(-65 \mathrm{ml})$ and precipitated salts were removed by filtration. To the completely dried syrup, obtained by repeated azeotropic distillation with EtOH, were added $\mathrm{Ac}_{2} \mathrm{O}(300 \mathrm{ml})$ and anhyd. $\mathrm{AcONa}(30 \mathrm{~g})$ : the mixture was heated for $2 \mathrm{hr}$ on a steam bath, and then poured into ice- $\mathrm{H}_{2} \mathrm{O}(2$ liter). The resulting precipitate was collected by filtration, and dried in the air. The light brown powder $(46 \mathrm{~g})$ was dissolved in $\mathrm{CH}_{2} \mathrm{Cl}_{2}(140 \mathrm{ml})$, the solution was decolorized with carbon, and concentrated to half-volume. Addition of petroleum ether (bp $30-60^{\circ}$ ) caused formation of a precipitate $(42 \mathrm{~g}, 90 \%), \mathrm{mp} 205^{\circ}$, which was used for further experiment. One recrystallization from

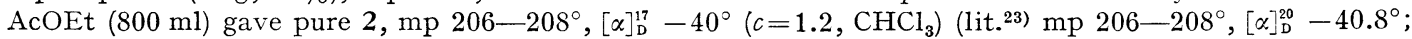
lit. ${ }^{1)} \mathrm{mp} 208^{\circ},[\alpha]_{\mathrm{D}}^{19}-39.3^{\circ}$.

Benzyl $2,3,2^{\prime}, 3^{\prime}, \mathbf{4}^{\prime}, \mathbf{6}^{\prime}$-Hexa-0-acetyl-6-0-methylsulfonyl- $\boldsymbol{\beta}$-lactoside (4)_-Hepta-O-acetyl-6-O-methylsulfonyl- $\beta$-lactose (3) was prepared according to the method as described in Part I.

Bromine $(2.5 \mathrm{ml})$ was added dropwise under $20^{\circ}$ to a suspension of red phosphorus $(1.5 \mathrm{~g})$ in glacial $\mathrm{AcOH}(15 \mathrm{ml})$ with external cooling. To this brominating reagent was added finely powdered $3(5 \mathrm{~g}, 7 \mathrm{mmole})$ in one portion, and the suspension was stirred for $3 \mathrm{hr}$. Dichloromethane $(30 \mathrm{ml})$ was added, and the mixture was poured into ice- $\mathrm{H}_{2} \mathrm{O}(300 \mathrm{ml})$, stirred for $30 \mathrm{~min}$ at $0^{\circ}$, and filtered. The organic layer was separated, successively washed with $\mathrm{H}_{2} \mathrm{O}$ and aq. $\mathrm{NaHCO}_{3}$ solution, dried $\left(\mathrm{MgSO}_{4}\right)$, and evaporated, to give a syrupy bromide which was used without further purification. To the bromide were added mercuric cyanide $(1.8 \mathrm{~g}$, $7.1 \mathrm{mmole})$ and benzyl alcohol $(10 \mathrm{ml}, 97.2 \mathrm{mmole})$. The mixture was heated on a boiling water bath for $1 \mathrm{hr}$, and then hot EtOH $(50 \mathrm{ml})$ was added to effect dissolution, and it was kept overnight at room temperature to crystallize. The crystals were collected by filtration, and recrystallized from a mixture of EtOH $(50$ $\mathrm{ml})$ and AcOEt $(50 \mathrm{ml})$, to give pure $4(2.4 \mathrm{~g}, 45 \%), \mathrm{mp} 191.5-192.5^{\circ},[\alpha]_{\mathrm{D}}^{14}-30^{\circ}\left(c=0.6, \mathrm{CHCl}_{3}\right) ; \mathrm{IR}_{\max }^{\mathrm{KBr}}$ : $1163 \mathrm{~cm}^{-1}\left(\mathrm{MeSO}_{2}\right)$; NMR: 2.80 (5-proton singlet, aryl), 6.90 (3-proton singlet, $\mathrm{MeSO}_{2}$ ), 7.85, 7.91, 7.93, 7.97, 8.00, 8.02 (18 protons, singlets, $6 \mathrm{AcO}$ ); TLC: Rf 0.57 (solvent A), 0.20 (B). Anal. Calcd. for $\mathrm{C}_{32} \mathrm{H}_{42} \mathrm{O}_{19} \mathrm{~S}$ : C, $50.38 ; \mathrm{H}, 5.56$. Found: $\mathrm{C}, \overline{5} 0.10 ; \mathrm{H}, 5.51$.

Benzyl 2,3,2', $\mathbf{3}^{\prime}, 4^{\prime}, 6^{\prime}$-Hexa-0-acetyl-6-deoxy-6-iodo- $\beta$-lactoside (5)—A mixture of 4 (500 mg, 656 mmole), with NaI (375 mg, 2.5 mole) in acetonitrile $(12 \mathrm{ml})$ was boiled for $9 \mathrm{hr}$ under reflux; sodium methanesulfonate soon began to precipitate. The suspension was filtrated, and the filtrate was evaporated to dryness. The residue was triturated with ice- $\mathrm{H}_{2} \mathrm{O}(10 \mathrm{ml})$, to afford a white solid which was collected by filtration. The air-dried powder was recrystallized from $\mathrm{EtOH}$, to give pure $\mathbf{5}(469 \mathrm{mg}, 90 \%), \mathrm{mp} 184-185^{\circ},[\alpha]_{\mathrm{D}}^{25}-35.1^{\circ}$ $\left(c=1.14, \mathrm{CHCl}_{3}\right)$; TLC: Rf 0.86 (solvent A), $0.58(\mathrm{~B})$, Anal. Calcd. for $\mathrm{C}_{31} \mathrm{H}_{39} \mathrm{O}_{16} \mathrm{I}: \mathrm{C}, 46.86 ; \mathrm{H}, 4.95$. Found: C, $46.68 ; \mathrm{H}, 4.93$.

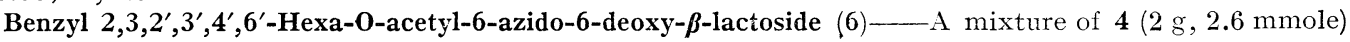
with $\mathrm{NaN}_{3}(1 \mathrm{~g}, 15.4 \mathrm{mmole})$ in HMPA $(10 \mathrm{mi})$ was heated on a boiing water bath for $7 \mathrm{hr}$. After the mixture was diluted with $\mathrm{H}_{2} \mathrm{O}(40 \mathrm{ml})$, it was extracted with AcOEt $(3 \times 10 \mathrm{ml})$, and the extracts were combined, washed with $\mathrm{H}_{2} \mathrm{O}$ dried $\left(\mathrm{Na}_{2} \mathrm{SO}_{4}\right)$, and evaporated to a syrup which crystallized from EtOH. The crystals were collected by filtration, and recrystallized from EtOH, to give pure $6(1.4 \mathrm{~g}, 74 \%), \mathrm{mp} 148.5-149.5^{\circ}$, $[\alpha]_{\mathrm{D}}^{15}-6.5^{\circ}\left(c=0.31, \mathrm{CHCl}_{3}\right)$; IR $\nu_{\max }^{\mathrm{KBr}}: 2100 \mathrm{~cm}^{-1}\left(\mathrm{~N}_{3}\right) ;$ NIR: 2.80 (5-proton singlet, aryl), 7.82, $7.92,8.00$ $\left(18\right.$ protons, singlets, $6 \mathrm{AcO}$ ); TLC: Rf 0.76 (solvent A), 0.47 (B). Anal. Calcd. for $\mathrm{C}_{31} \mathrm{H}_{39} \mathrm{O}_{16} \mathrm{~N}_{3}: \mathrm{C}, 52.47$; $\mathrm{H}, 5.54 ; \mathrm{N}, 5.92$. Found: $\mathrm{C}, 52.76 ; \mathrm{H}, 5.60 ; \mathrm{N}, 5.7 \mathrm{i}$.

Benzyl 2,3,2',3',4',6'-Hexa-0-acetyl-6-acetamido-6-deoxy- $\beta$-lactoside (7)—A solution of 6 (1.4 g) in $\mathrm{MeOH}(30 \mathrm{ml})$ was hydrogenated for $4 \mathrm{hr}$ at atmospheric pressure in the resence of freshly prepared Raney nickel catalyst. After removal of the catalyst by filtration, the filtrate and washings were concentrated to dryness, to give a syrup which was acetylated with $\mathrm{Ac}_{2} \mathrm{O}(5 \mathrm{ml})$ and pyridine $(5 \mathrm{ml})$ for $24 \mathrm{hr}$ at room temperature. The syrup, obtained by repeated azeotropic distillation with toluene, was dissolved in $\mathrm{CH}_{2} \mathrm{Cl}_{2}$, and the solution was chromatographed on a column of silica gel using $3: 1(\mathrm{v} / \mathrm{v}) \mathrm{CHCl}_{3}$-acetone as elusion solvent. Evaporation of the faster moving eluate afforded a syrup which crystallized from EtOH. The product $(332 \mathrm{mg}, 23 \%)$ had $\mathrm{mp} 143-144^{\circ},[\alpha]_{\mathrm{D}}^{18}-56.8^{\circ}\left(c=0.95, \mathrm{CHCl}_{3}\right) ;$ IR $v_{\max }^{\mathrm{KBr}}: 3370(\mathrm{NH}), 1660 \mathrm{~cm}^{-1}$ (CONH) ; NMR: 2.63 (5-proton singlet, aryl), 4.13 (1-proton multiplet, NH), 7.85, 7.87, 7.95, $7.98,8.03$ (21 protons, singlets, NHAc + OAc); TLC: Rf 0.41 (solvent A), 0.05 (B). Anal. Calcd. for $\mathrm{C}_{33} \mathrm{H}_{43} \mathrm{O}_{17} \mathrm{~N}$ : C, 54.62 ; $\mathrm{H}, 5.97 ; \mathrm{N}, 1.93$. Found: $\mathrm{C}, 54.57 ; \mathrm{H}, 5.92 ; \mathrm{N}, 1.84$.

Further elution with the same solvent afforded small amounts of another crystals after removal of the solvent which were indistinguishable with compound $\mathbf{8}$.

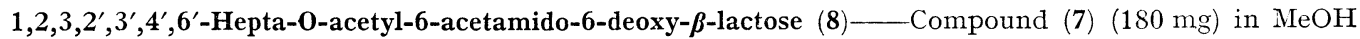
$(10 \mathrm{ml})$ was hydrogenated using Raney nickel catalyst as the preparation of 7 . After $6 \mathrm{hr}$, the catalyst was removed by filtration and the filtrate and washings were concentrated to dryness. The residue was acetylated

23) E.M. Montgomery, N.K. Richtmyer, and C.S. Hudson, J. Am. Chem. Soc., 65, 1848 (1943). 
with $\mathrm{Ac}_{2} \mathrm{O}(1 \mathrm{ml})$ and pyridine $(1 \mathrm{ml})$ in the usual way, to give a sirup which crystallized from iso-PrOHether. The crystals were collected by filtration and recrystallized from $n$-PrOH, to give pure 8 (135 mg, $81 \%), \operatorname{mp~} 102-103^{\circ},[\alpha]_{\mathrm{D}}^{19}-20.2^{\circ}\left(c=1.04, \mathrm{CHCl}_{3}\right) ; \operatorname{IR} \nu_{\max }^{\text {Nujol }}: 3300(\mathrm{NH}), 1665 \mathrm{~cm}^{-1}(\mathrm{CONH}) ;$ TLC:Rf 0.29 (solvent A), 0 (B). Anal. Calcd. for $\mathrm{C}_{28} \mathrm{H}_{39} \mathrm{O},{ }_{38} \mathrm{~N}: \mathrm{C}, 49.63 ; \mathrm{H}, 5.80 ; \mathrm{N}, 2.07$. Found: C, 49.51; $\mathrm{H}, 6.04 ; \mathrm{N}$, 1.81 .

6-Acetamido-6-deoxy-lactose (9)—To a solution of $8(400 \mathrm{mg})$ in dry $\mathrm{MeOH}(5 \mathrm{ml})$ was added $0.05 \mathrm{M}$ methanolic sodium methoxide $(1 \mathrm{ml})$ at room temperature. The mixture was stirred, with exclusion of moisture, for $30 \mathrm{~min}$; the complete deacetylation was checked by TLC. Dry Amberlite IR-120 $\left(\mathrm{H}^{+}\right)$resin was added, and the suspension was stirred for $30 \mathrm{~min}$, and then filtered. The filtrate was concentrated to dryness to give a syrup which was dissolved in aq. EtOH and kept for $24 \mathrm{hr}$ at $5^{\circ}$, to precipitate a jelly product. The product was collected by filtration and dried in a vacuum desiccator to afford a hygroscopic white powder $(170 \mathrm{mg}, 75 \%),[\alpha]_{\mathrm{D}}^{19}+32.3^{\circ}(c=0.62, \mathrm{MeOH}) ; \operatorname{IR} v_{\max }^{\text {Nujol }}: 3320(\mathrm{OH}), 1640 \mathrm{~cm}^{-1}(\mathrm{CONH}) ;$ TLC: Rf 0.39 (solvent C).

Paper Chromatography of Acid Hydrolyzate of Compound (9)—_Authentic 6-amino-6-deoxy-D-glucose hydrochloride, Rf 0.22 and positive reagent (A) or (B) test, was prepared according to the method of Hardegger, et al. ${ }^{24)} \quad$-Galactose has a $R f 0.38$ and gives a positive reagent (B) test.

A mixture of $9(100 \mathrm{mg}), R f 0.25$ and positive reagent $(\mathrm{B})$ or $(\mathrm{C})$ test, and $1 \mathrm{M} \mathrm{HCl}(4 \mathrm{ml})$ in a sealed tube was heated at $110^{\circ}$ for $3 \mathrm{hr}$. After treatment with carbon, the mixture was evaporated to dryness and a trace of $\mathrm{HCl}$ was removed completely by repeated azeotropic distillation with $\mathrm{EtOH}$ and then kept overnight in a desiccator containing $\mathrm{NaOH}$. The residue was dissolved in small amount of $\mathrm{H}_{2} \mathrm{O}$, in which $\mathrm{D}$-galactose ( $R f$ 0.38) and 6-amino-6-deoxy-D-glucose hydrochloride $(R f 0.22)$ were identified by paper chromatography.

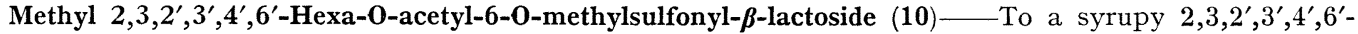
hexa-O-acetyl-6-O-methylsulfonyl bromide, prepared from 3 ( $5 \mathrm{~g}, 7 \mathrm{mmole})$ as described for the preparation of 4 , were added mercuric cyanide $(1.8 \mathrm{~g}, 7.1 \mathrm{mmole})$ and dry $\mathrm{MeOH}(20 \mathrm{ml}, 0.5 \mathrm{~mole})$, and the mixture was stirred for $3 \mathrm{hr}$ at room temperature, whereupon precipitates soon began to appear. After the solvent was evaporated from the mixture, the residue was treated with $\mathrm{CH}_{2} \mathrm{Cl}_{2}(50 \mathrm{ml})$ and filtered; the insoluble salts were discarded. The organic layer was washed with $\mathrm{H}_{2} \mathrm{O}$ until the washings gave no precipitate with $\mathrm{AgNO}_{3}$ solution, and then dried $\left(\mathrm{CaCl}_{2}\right)$, filtered, and concentrated to a syrup which crystallized from EtOH. The crystals were collected by filtration and recrystallized from $\mathrm{EtOH}$, to give pure $10(3 \mathrm{~g}, 63 \%), \mathrm{mp} 113-$ $114^{\circ},[\alpha]_{\mathrm{D}}^{21}-14.9^{\circ}\left(c=1.15, \mathrm{CHCl}_{3}\right)$, IR $v_{\max }^{\mathrm{Nujol}}: 1170 \mathrm{~cm}^{-1}\left(\mathrm{MeSO}_{2}\right)$; NMR: 6.42 (3-proton singlet, OMe), 6.80 (3-proton singlet, $\mathrm{MeSO}_{2}$ ), 7.80, 7.87, 7.98 (18 protons, singlets, $6 \mathrm{AcO}$ ); TLC: Rf 0.60 (solvent A). Anal. Calcd. for $\mathrm{C}_{26} \mathrm{H}_{38} \mathrm{O}_{19} \mathrm{~S}: \mathrm{C}, 45.48 ; \mathrm{H}, 5.58$. Found: $\mathrm{C}, 45.19 ; \mathrm{H}, 5.83$.

Methyl 2,3,2, $\mathbf{3}^{\prime}, 4^{\prime}, 6^{\prime}$-Hexa-0-acetyl-6-deoxy-6-iodo- $\beta$-lactoside (11)-A mixture of $10 \quad(500 \mathrm{mg}$, $729 \mathrm{mmole})$ with $\mathrm{NaI}$ (375 mg, $2.5 \mathrm{~mole})$ in acetonitrile $(12 \mathrm{ml})$ was boiled for $8 \mathrm{hr}$ under reflux; sodium methanesulfonate soon began to precipitate. The mixture was similarly treated as described for the prepartion of 5 , to afford pure $11(470 \mathrm{mg}, 90 \%), \mathrm{mp} 166-167^{\circ},[\alpha]_{\mathrm{D}}^{22}-10^{\circ}\left(c=1.02, \mathrm{CHCl}_{3}\right)$; TLC: Rf 0.71 (solvent A), 0.50 (B). Anal. Calcd. for $\mathrm{C}_{25} \mathrm{H}_{35} \mathrm{O}_{16} \mathrm{I}: \mathrm{C}, 41.80 ; \mathrm{H}, 4.91$. Found: $\mathrm{C}, 41.74 ; \mathrm{H}, 4.84$.

Methyl 2,3,2',3', $\mathbf{4}^{\prime}, \mathbf{6}^{\prime}$-Hexa-0-acetyl-6-azido-6-deoxy- $\boldsymbol{\beta}$-lactoside (12)-A mixture of $10(2 \mathrm{~g}, 2.9 \mathrm{mmole})$ with $\mathrm{NaN}_{3}(1 \mathrm{~g}, 15.4 \mathrm{mmole})$ in HMPA $(10 \mathrm{ml})$ was heated on a boiling water bath for $4 \mathrm{hr}$. The mixture was treated as described for the preparation of 6 , to give pure $12(1.5 \mathrm{~g}, 82 \%), \mathrm{mp} 200-201^{\circ},[\alpha]_{\mathrm{D}}^{22}+6^{\circ}(c=1$, $\mathrm{CHCl}_{3}$ ), IR $\nu_{\max }^{\text {Nujol }}: 2100 \mathrm{~cm}^{-1}\left(\mathrm{~N}_{3}\right)$; NMR: 6.42 (3-proton singlet, OMe), 7.80, 7.88, 7.98 (18 protons, singlets, $6 \mathrm{AcO}$ ); TLC: Rf 0.74 (solvent A), 0.44 (B). Anal. Calcd. for $\mathrm{C}_{25} \mathrm{H}_{35} \mathrm{O}_{16} \mathrm{~N}_{3}: \mathrm{C}, 47.39 ; \mathrm{H}, 5.57 ; \mathrm{N}, 6.63$. Found: $\mathrm{C}, 47.13 ; \mathrm{H}, 5.53 ; \mathrm{N}, 6.45$.

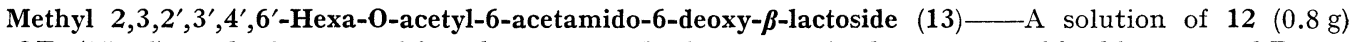
in AcOEt $(25 \mathrm{ml})$ was hydrogenated for $3 \mathrm{hr}$ at atmospheric pressure in the presence of freshly prepared Raney nickel catalyst. After removal of the catalyst by filtration, the filtrate and washings were concentrated to dryness, to give a syrup which was dissolved in dry $\mathrm{MeOH}(5 \mathrm{ml})$ and added $\mathrm{Ac}_{2} \mathrm{O}(3 \mathrm{ml})$. The solution was kept overnight at room temperature. The syrup, obtained by repreated azeotropic distillation with toluene, was dissolved in EtOH and crystallized on adding ether followed by scratching inside of the flask. Recrystallization from EtOH-ether afforded pure $13(0.6 \mathrm{~g}, 72 \%), \mathrm{mp} 200-201^{\circ},[\alpha]_{\mathrm{D}}^{22}-50^{\circ}\left(c=1.04, \mathrm{CHCl}_{3}\right)$; IR $v_{\max }^{\text {Nujol }}: 3360(\mathrm{NH}), 1678(\mathrm{CONH}) \mathrm{cm}^{-1}$; NMR: 3.88 (1-proton multiplet, NH), 6.43 (3-proton singlet, OMe), 7.82, 7.90, 7.98 (21 protons, singlets, NHAc +6 AcO); TLC: Rf 0.22 (solvent A), 0 (B). Anal. Calcd. for $\mathrm{C}_{27} \mathrm{H}_{39} \mathrm{O}_{17} \mathrm{~N}: \mathrm{C}, 49.92 ; \mathrm{H}, 6.05 ; \mathrm{N}, 2.16$. Found: $\mathrm{C}, 49.62 ; \mathrm{H}, 6.02 ; \mathrm{N}, 2.17$.

Methyl 6-Acetamido-6-deoxy- $\boldsymbol{\beta}$-lactoside (14)_-To a solution of $\mathbf{1 3}(0.2 \mathrm{~g})$ in dry $\mathrm{MeOH}(3 \mathrm{ml})$ was added $0.05 \mathrm{~m}$ methanolic sodium methoxide $(0.5 \mathrm{ml})$ at room temperature. The mixture was similarly treated as described for the preparation of $\mathbf{9}$, to afford a syrup which was dissolved in EtOH (2 ml) and added ether $(2 \mathrm{ml})$; crystallization occurred after $5 \mathrm{hr}$ in a refrigerator. The crystals were collected by filtration and recrystallized from $\mathrm{MeOH}$ to give pure $14(86 \mathrm{mg}, 70 \%)$, hygroscopic crystals, $\mathrm{mp} 166-167^{\circ},[\alpha]_{\mathrm{D}}^{23}+4^{\circ}(c=$ $\left.1.06, \mathrm{H}_{2} \mathrm{O}\right)$; IR $v_{\max }^{\text {Nujol }}: 3300(\mathrm{OH}), 1650(\mathrm{CONH}) \mathrm{cm}^{-1}$; TLC: Rf 0.43 (solvent C). Anal. Calcd. for $\mathrm{C}_{15} \mathrm{H}_{27} \mathrm{O}_{11} \mathrm{~N}$ : $\mathrm{C}, 45.34 ; \mathrm{H}, 6.85 ; \mathrm{N}, 3.52$. Found: $\mathrm{C}, 45.62 ; \mathrm{H}, 6.91 ; \mathrm{N}, 3.58$.

24) E. Hardegger, G. Zanetti, and K. Steiner, Helv. Chim. Acta, 46, 282 (1963). 
Paper Chromatography of Acid Hydrolyzate of Compound (14)—_Authentic methyl 6-amino-6-deoxy- $\beta$ D-glucoside hydrochloride, $R f 0.28$ and positive reagent (A) test, 6-acetamido-6-deoxy-D-glucose, $R f 0.47$ and positive reagent $(\mathrm{B})$ or $(\mathrm{C})$ test, and methyl 6 -acetamido-6-deoxy- $\beta$-D-glucoside, $R f$ 0.54 and positive reagent $(\mathrm{C})$ test, were prepared according to the method as described in lit. ${ }^{24}$

Hydrolysis of $14(0.1 \mathrm{~g})$ and treatment of the hydrolyzate were performed similarly with the method as described in that of 9 . Paper chromatography of the hydrolyzate clarified that D-galactose $(R f 0.38)$ and 6-amino-6-deoxy-D-glucose hydrochloride $(R f 0.22)$ were identified as major spots along with three minor spots, methyl 6-amino-6-deoxy- $\beta$-D-glucoside hydrochloride ( $R f$ 0.28), 6-acetamido-6-deoxy-D-glucose $(R f$ 0.47 ), and methyl 6-acetamido-6-deoxy-D-glucoside ( $R f$ 0.54).

Preliminary Bioassay-6-Acetamido-6-deoxy-lactose (9), in a dilution of 1: 1000, did not show antibacterial activity against 20 kinds of microorganisms; five strains of Staphylococcus, 4 Salmonellas, 3 E. colis, 3 Shigellas, B. subtilis, $P$. aeruginosa, $K$. pneumoniae, prot vulgaris, and Str. faecalis.

Acknowledgement The authors express sincere thanks to Dr. Kuzuhara (The Institute of Physical and Chemical Research) for experimental advice. We also thank to S. Itoh and T. Ban for the microanalyses. Antimicrobial test was performed in Department of Microbiology, Tokyo Laboratory, Kowa Company Ltd., to which the authors are grateful. 